\title{
Range Extension of the Black-banded Trinket Snake, Oreocryptophis porphyraceus (Cantor 1839) in Lam Dong Province, Vietnam
}

Sebastian Hoefer

Department of Biology, Freie Universität Berlin, 14195 Berlin, Germany (sebastianhoefer@outlook.com)

$\mathrm{T}$ The Black-banded Trinket Snake (Oreocryptophis porphyraceus) is a medium-sized colubrid found in China, Taiwan, India, Nepal, Myanmar, Laos, Thailand, Cambodia, Malaysia, Indonesia, and Vietnam (Nguyen et al. 2009). In Vietnam the known distribution of $O$. porphyraceus has been limited to the northern provinces where it often inhabits montane forests with elevations exceeding $800 \mathrm{~m}$ (Ziegler et al. 2004; Nguyen et al. 2009; Son and Truong 2014; Das 2016; Van Tan and Truong 2016; Le et al. 2018).

On 2 March 2019 at $2211 \mathrm{~h}$, colleagues and I found a Black-banded Trinket Snake crossing a stream (Fig. 1) in the western highlands of Lam Dong Province $\left(11.4475^{\circ} \mathrm{N}\right.$, $108.0648^{\circ} \mathrm{E}$; WGS $84 ; 1,281 \mathrm{~m}$ asl). The landscape of this area is dominated by tropical montane evergreen forest. Based on criteria listed by Das (2016), we assigned this snake to the subspecies O. p. vaillanti. Snout-vent length (SVL) was 61.5 $\mathrm{cm}$ and total length (TL) $76 \mathrm{~cm}$. Some damage to the left eye was evident (Fig. 2).

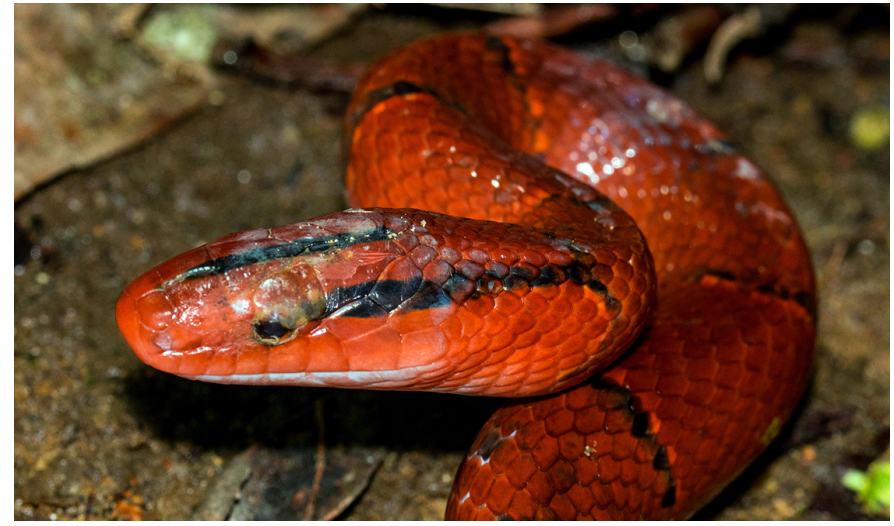

Fig. 2. Visible damage to the left eye of a Black-banded Trinket Snake (Oreocryptophis porphyraceus) found on 2 March 2019 in Lam Dong Province, Vietnam. Photograph by the author.

The most southerly previously published record of $O$. porphyraceus in Vietnam was from Quang Binh Province (Fig.
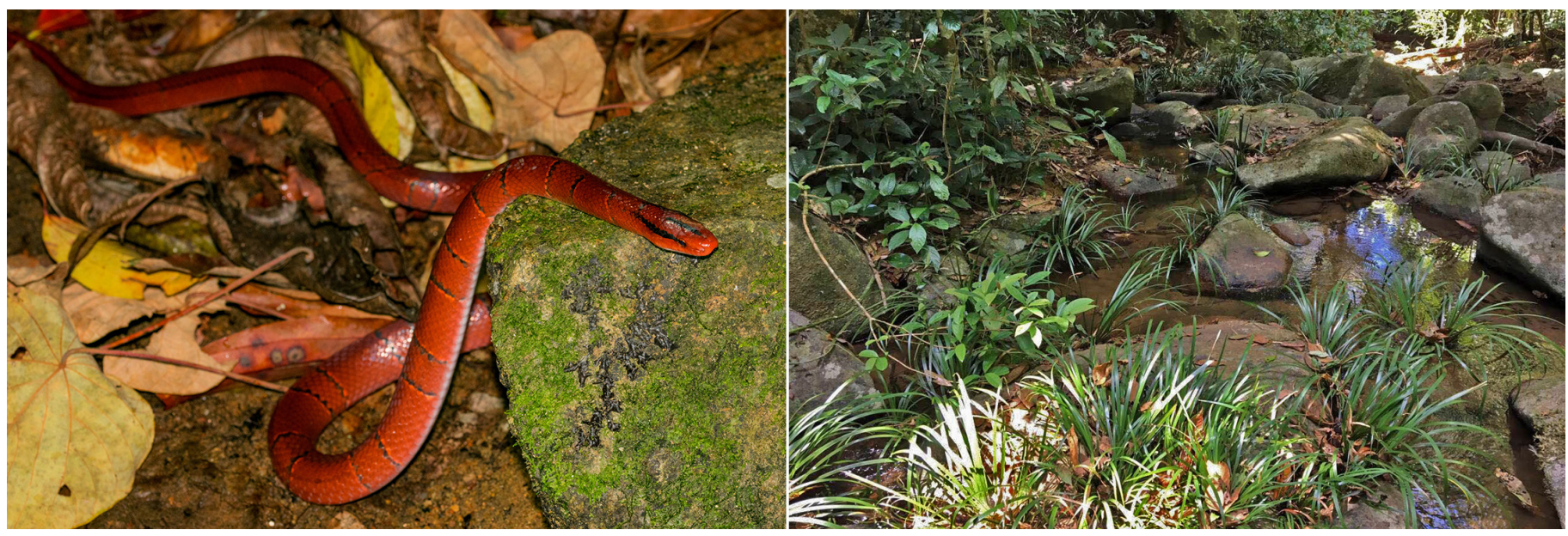

Fig. 1. A Black-banded Trinket Snake (Oreocryptophis porphyraceus) found on 2 March 2019 in Lam Dong Province, Vietnam, and habitat at the site where the snake was encountered. Photographs by the author (left) and Khoa Nguyen (right). 


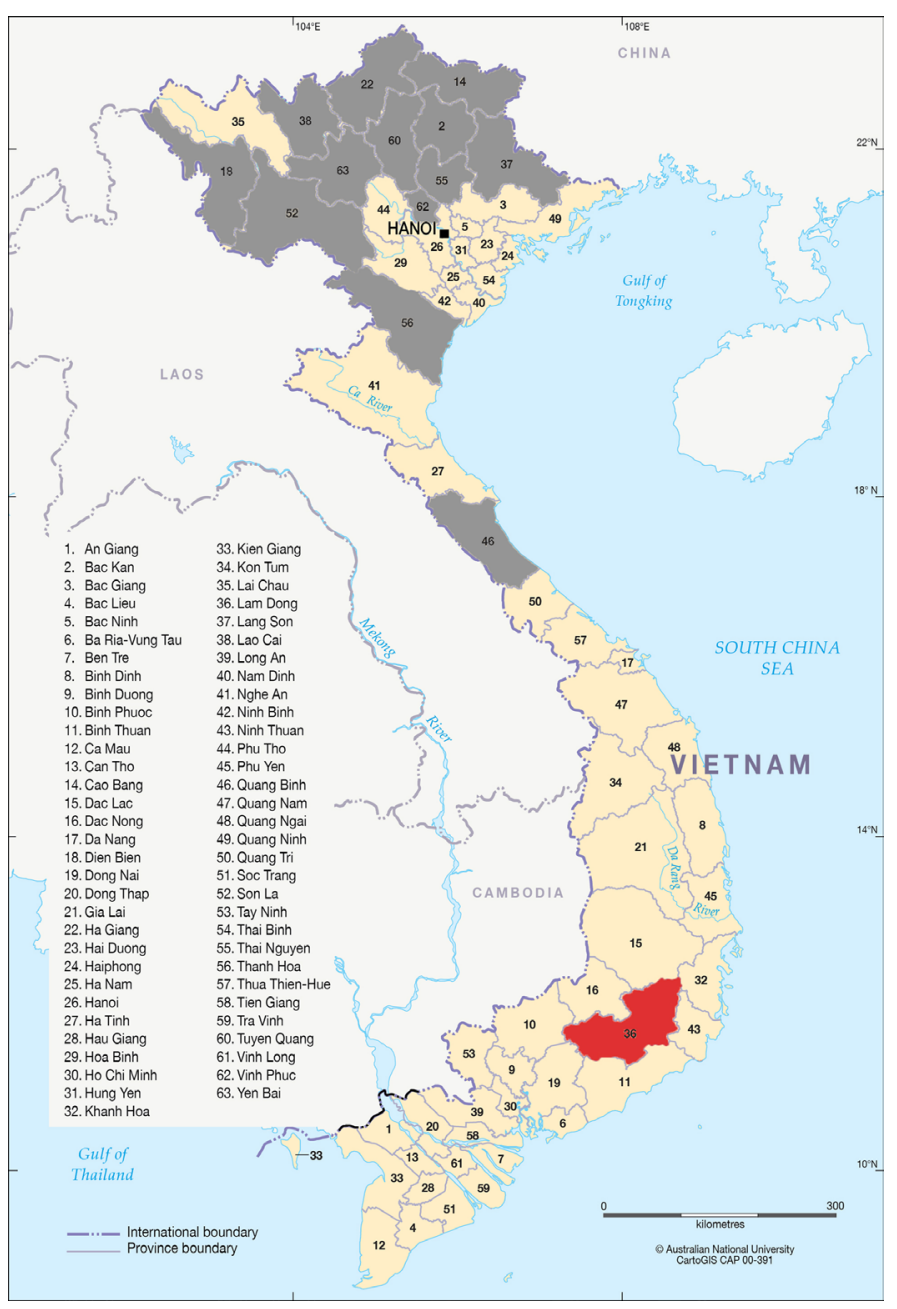

Fig. 3. Map of Vietnam (http://asiapacific.anu.edu.au/mapsonline/basemaps/vietnam-provinces) showing the previously known distribution of the Black-banded Trinket Snake (Oreocryptophis porphyraceus) in gray and the range extension in Lam Dong Province in red.
3; Ziegler et al. 2004). This record extends the distribution to Lam Dong Province and is the first report of the species in southern Vietnam.

\section{Acknowledgements}

Nguyen Huy, Nguyen Linh, and Hieu Pham Minh provided company and hospitality during my stay in Phan Thiet and helped find some information for this note.

\section{Literature Cited}

Das, I. 2016. A Field Guide to the Reptiles of South-East Asia. New Holland Publishers, London, United Kingdom.

Le, D.T., A.N. Dao, D.T. Pham, T. Ziegler, and T.Q. Nguyen. 2018. New records and an updated list of snakes from Yen Bai Province, Vietnam. Herpetology Notes 11: 101-108.

Nguyen, V., T. Ho, and Q. Nguyen. 2009. Herpetofauna of Vietnam. Edition Chimaira, Frankfurt am Main, Germany.

Son, N.L.H. and N.Q. Truong. 2014. New records of snakes (Squamata: Serpentes) from Dien Dien Province. Tap chi Sinh hoc 36: 460-470.

Van Tan, N. and N.Q. Truong. 2016. New records and an updated list of snakes (Squamata: Serpentes) from Xuan Lien Nature Reserve, Thanh Hoa Province, Vietnam. Academia Journal of Biology 38: 324-332.

Ziegler, T., H.-W. Herrmann, V.N. Thanh, L.K. Quyet, N. Hie, C.X. Chinh, L.M. Thanh, and D.H. Tri. 2004. The amphibians and reptiles of the Phong Nha-Ke Bang National Park, Quang Binh Province, Vietnam. Hamadryad 28: $19-42$. 